\section{$\square$} LIBROS

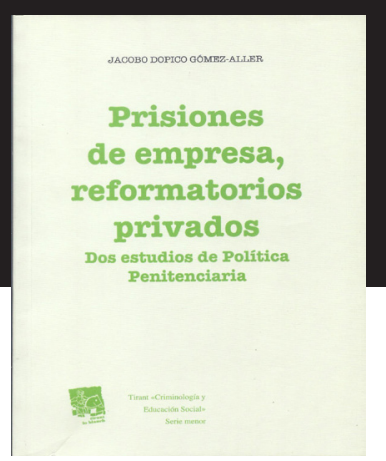

Jacobo Dopico Gómez-Aller, "Prisiones

de empresa, reformatorios privados. Dos estudios de Política Penitenciaria" Valencia:

Tirant lo Blanch, serie menor 'Criminología y

Educación Social', 2011, 119 páginas.

\title{
Prisiones de empresa, reformatorios privados. Dos estudios de Política Penitenciaria
}

Este libro constituye un aporte importante acerca de la política penitenciaria desde una revisión sistemática y lúcida de dos casos relevantes.

El primer caso está referido a la experiencia norteamericana reciente con la privatización de centros de reclusión, un modelo emblemático y muy estudiado en la literatura anglosajona; el cual se aborda de manera técnica con una breve historia del fenómeno en Estados Unidos y las fórmulas que la participación privada ha adoptado en la actualidad (en servicios de construcción, alimentación, seguridad y hasta gestión integral de centros), abordando aristas fundamentales como la inversión pública, el ahorro público, conflictos de interés, eficiencia, competencia, regulación, reinserción, presencia de lucro empresarial, entre otros. Del estudio de este caso se sistematizan posturas contrapuestas lo cual es de mucha utilidad para la ubicación de discursos en la política penitenciaria. Además, se logra hacer un análisis técnico de la influencia del neoliberalismo en la privatización de cárceles, distinguiendo este frente de lucro privado como uno de los menos ambicionados por los consorcios, no por que no sea altamente beneficioso, sino por los costos que representa en cuanto a atención a leyes, derechos y por tratarse de un rubro sinuoso en materia de gestión empresarial. Sin embargo, el fenómeno se ha extendido paulatinamente por el mundo occidental desarrollado.

El otro caso de estudio es España, el cual se delimita a la privatización de correccionales juveniles, ahí se abordan las mismas aristas apuntadas en la sección anterior, con el agregado de polemizar sobre la penalidad juvenil en tanto se trata de uno de los campos de punición más debatidos en vista de los índices crecientes de delincuencia juvenil.

El libro es relevante en tanto ofrece estadísticas de la privatización penitenciaria en España, realizando análisis cualitativos acerca de quiénes son los gestores privados de penitenciarías, sus nexos con funcionarios públicos, el análisis de las Comunidades Autónomas y su actuación al respecto, el acaparamiento del mercado, la relación de costos y beneficios para el Estado, resultados en materia de rehabilitación, entre otros análisis relevantes. Además, se encuentra en él un potencial de uso para los estudiosos del derecho penal por la abundancia de análisis acerca de la legislación respectiva en España.

Finalmente, es destacable la presencia de una buena cantidad de bibliografía en español (también en inglés) referida al tema, algo que sería de utilidad para los investigadores interesados en profundizar sus estudios. De hecho, la editorial 
Tirant lo Blanch ofrece buena cantidad de bibliografía especializada en materia de seguridad pública, criminología y otros campos conexos.

Sinopsis a cargo de Augusto Rigoberto López Ramírez Investigador Asistente del CINC-ANSP 